\title{
Analysis of Factors Influencing Childbirth Preparation in Margamulya Cikunir Village Singaparna Area Public Health Center Tasikmalaya
}

\author{
$1^{\text {st }} \mathrm{S}$ Susanti \\ STIKes Respati Tasikmalaya \\ West Java, Indonesia \\ santiazhari@gmail.com
}

\author{
$2^{\text {nd }}$ A Rahmidini \\ STIKes Respati Tasikmalaya \\ West Java, Indonesia
}

\author{
$3^{\text {rd }}$ CY Hartini \\ STIKes Respati Tasikmalaya \\ West Java, Indonesia
}

\begin{abstract}
The maternal mortality rate provides an overview of the nutritional status and health of the mother, socioeconomic conditions, environmental health and the level of health services, especially maternal health services. The birth planning program or preparation for labor is an important component considering that maternal mortality is more common during labor. The general objective of the study was to analyze the factors affecting the preparation of childbirth in pregnant women in the Margamulya hamlet in the village of Cikunir, the working area of the Singaparna Public Health Center. This research uses quantitative research methods with cross sectional approach. The population in this study were pregnant women in Margamulya sub-village, Cikunir village, Singaparna public health center. The research sample uses a total sampling of 41 people. This type of data uses secondary data. Data analysis uses the method Structural Equation Modeling (SEM). The results of the study are known factors of education, age, Maternal and Child Health Book (MCH Handbook) influence on labor preparation. Meanwhile, parity, and Antenatal care (ANC) factors do not affect labor preparation. The contribution of the influence of education, gestational age, parity, MCH handbook, high risk, and ANC were $72.4 \%$, the rest was influenced by other factors not included in this study. The conclusion of the research is the factors that influence the preparation of childbirth for pregnant women are the factors of education, age and ownership of the MCH handbook. Pregnant women should do ANC and take classes in pregnant women so that they will get information about childbirth preparation.
\end{abstract}

\section{Keywords-Childbirth, Public Health, Tasikmalaya}

\section{INTRODUCTION}

Maternal Mortality Rate (MMR) describes the maternal mortality rate due to pregnancy, childbirth and the puerperium for every 100,000 live births in a given region and time. This figure provides an overview of the nutritional status and maternal health, socioeconomic conditions, environmental health and the level of health services, especially maternal health services (health of pregnant women, childbirth and postpartum mothers). Mothers have a high risk during childbirth in several countries, especially developing countries and developing countries. According to WHO reports, maternal deaths generally occur as a result of complications during, and after pregnancy. The types of complications that cause the majority of cases of maternal death - about $75 \%$ of the total cases of maternal death - are bleeding, infection, high blood pressure during pregnancy, childbirth complications, and unsafe abortion. For the case of Indonesia itself, based on data from the Health and Information Center of the Ministry of Health (2014) the main causes of maternal deaths from $2010-2013$ were bleeding (30.3\% in 2013) and hypertension $(27.1 \%$ in 2013). This is very ironic, considering the various causes of maternal death above can actually be prevented, if the mother gets the right medical treatment $[1,2]$.

In Indonesia the maternal mortality rate is among the highest in the Southeast Asian region. According to UNESCAP data, the maternal mortality rate in Indonesia is 220/100.000 live births. This figure is the fourth highest mortality rate among countries in Southeast Asia. Based on the 2012 Indonesian Demographic and Health Survey, the maternal mortality rate (MMR) related to pregnancy, childbirth and childbirth is 359 / 100,000 live births. The target of reducing MMR in Indonesia in 2015 is 102 per 100,000 live births [3]. The increase in MMR is not only a matter of maternal health, but also the existence of gender inequality and injustice. Low public awareness of the health of pregnant women also affects the MMR. This can be seen from the many factors of 3 (three) T, which are: Too late to reach the facility; Too late getting help; and Late recognizing danger signs of pregnancy and childbirth. It is also caused by 4 (four) Ter: Too young; Too old; Too often give birth and too much. Causes of maternal deaths are directly related to the medical,associated with obstetric complications during pregnancy, childbirth and postnatal (postpartum). Various studies have found that the most causes of maternal death are due to bleeding. Some causes of maternal death are bleeding, eclampsia, old parturition, abortion complications, and infection [3,4] (Ministry of Women's Empowerment and Child Protection, 2016). 
Various efforts have been made to reduce the death of mothers, newborns, infants and toddlers. Among others through the placement of midwives in the village, empowering families and communities by using the Maternal and Child Health Book (MCH Handbook) and the Birth Planning and Complications Prevention Program (P4K), and the Participation of Women's Organizations in Reducing Mortality Rate health facilities providing health facilities Basic Emergency Neonatal Obstetric Services (PIA) PONED) in the Community Health Care and Neonatal Comprehensive Emergency Obstetric Service (PONEK) at the Hospital. (Ministry of Women's Empowerment and Child Protection., 2016). The birth planning program or preparation for labor is an important component considering that maternal mortality is more common during labor. Assistance with the delivery of skilled health workers is one of the most effective ways to reduce MMR in Indonesia. The percentage of deliveries assisted by trained health workers according to 2009 National Socioeconomic Survey data increased from $66.7 \%$ in 2002 to $77.34 \%$ in 2009.

Labor preparation is every component that must be prepared by pregnant women to deal with childbirth which includes birth attendant planning. , preparation of maternal and infant equipment, preparation of maternity savings (funds), transportation preparation, and blood donor preparation. Based on the health profile of Tasikmalaya district in 2018 the delivery assistance by health workers in Tasikmalaya Regency in 2017 was 90\%. While the achievement of delivery assistance by health workers in Singaparna public health centers is below the standard of $80.8 \%$. Based on this, it is important to conduct research on the analysis of factors that affect labor preparation. This study provides benefits for midwives in knowing the factors that influence pregnant women in preparing for delivery, so that it can help midwives implement the most dominant variables that influence it.

\section{METHOD}

The research method uses quantitative withapproach cross sectional. The population in this study were pregnant women in Margamulya sub-village, Cikunir village, Singaparna Public Health Center working area. The research sample uses a total sampling of 41 pregnant women. The data used are secondary data obtained from actual practical work activities of midwifery study program students in Cikunir village in 2018. The instrument uses the check list format. Data analysis using Structural Equation Modeling (SEM) analysis.

Results of the study were obtained as follows:

\section{RESULTS}

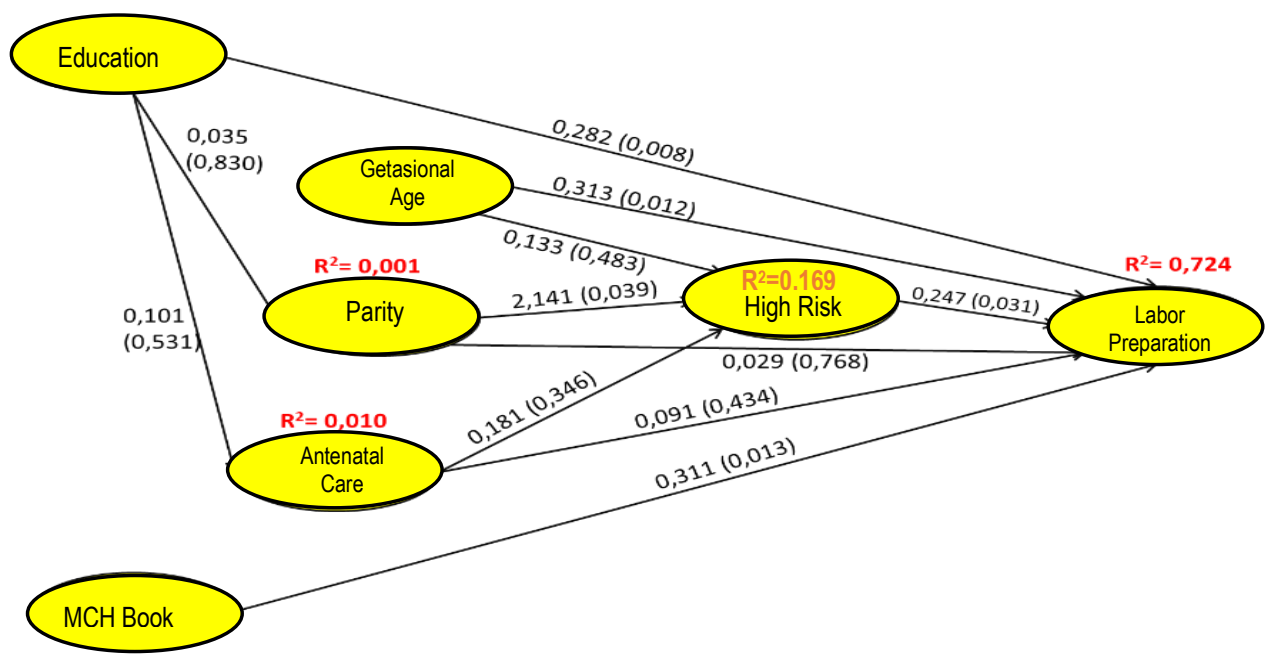

Fig. 1. Analisys of factors influencing childbirth preparation in Margamulya Cikunir Village Singaparna Public Health Center Working Area

Based on the picture above, it is known that the analysis of Education factors on labor preparation obtained a significance value of $\mathrm{p}=0.008<0.05$, thus there is a significant influence of labor factors on labor preparation. Analysis of gestational age factors for the preparation of labor obtained a significance value of $p=0.012<0.05$, then the gestational age factor has a significant direct effect on labor preparation. Parity factor analysis of labor preparation obtained a significance value of $\mathrm{p}=0.768>$ 0.05 , so it can be concluded that the parity factor does not affect labor preparation. ANC factor analysis of labor preparation obtained a significance value of $p=0.434$ >
0.05, then the ANC factor does not affect the preparation of labor.

Analysis of the $\mathrm{MCH}$ Handbook factor on labor preparation obtained a significance value of $\mathrm{p}=0.013$ $<0.05$, thus the $\mathrm{MCH}$ Handbook factor has a significant direct effect on labor preparation. $\mathrm{R}^{2}$ value $=0.724$ in labor preparation factors, meaning that the contribution of the influence of the factors of education, gestational age, parity, $\mathrm{MCH}$ handbook, high risk, and ANC is $72.4 \%$, the rest is influenced by other factors not included in this study. This effect is quite good because this study found that labor preparation was influenced by $<50 \%$ by the predicted factors. 
Analysis of gestational age, parity, and ANC on High Risk of Pregnant women, obtained significance values of gestational age $\mathrm{p}=0.483$, parity $\mathrm{p}=0.039$, and ANC $\mathrm{p}=$ 0.346 , so it can be concluded that only parity affects the risk of maternal pregnancy. Based on the value of $\mathrm{R}^{2}=$ 0.169 on risk factors, which means that the contribution of factors influence gestational age, parity, and the ANC is only $16.9 \%$, the rest influenced by other factors not entered into this study.

\section{DISCUSSION}

\section{A. Education}

Based on the figure 1 analisys of factors influencing childbirth preparation in Margamulya Cikunir Village Singaparna Public Health Center Working Area, it is known that the Education factor analysis of labor preparation obtained a significance value of $p=0.008$ $<0.05$, so it can be concluded that there is a significant direct effect of labor factors on labor preparation. This is in line with research conducted by Sugiyanti (2009) who found there is an influence between education and labor preparation. In this case the authors analyze that the higher the level of education of pregnant women will facilitate the acceptance of health information delivered by midwives / doctors, especially in information about childbirth preparation and prevention of complications. With the information provided by maternal officers with a high level of education it will be easier to understand messages compared to a low level of education [5].

The level of education is very closely related to the degree of health. The higher the level of education, the higher the awareness about the right to get health services in meeting health needs so that it will increase demands on the right to receive / reject health services / treatment. The emergence of healthy behaviors, such as childbirth preparation for pregnant women is based on an understanding of health that comes from education. Education is one indicator that is able to reflect the ability of the intellectual power of pregnant women in their work, thus having an influence on their ignorance of information related to labor preparation. This is consistent with the theory that the higher a person's education, the higher the awareness of the importance of health so that it will increase demands on the right to receive and reject health services or treatment [6].

\section{B. Pregnancy Age}

Factor Analysis of gestational age for the preparation of labor obtained a significance value of $p=0.012<0.05$, so it can be concluded that the gestational age factor has a direct significant effect on labor preparation. In this study it was found that with increasing gestational age, the awareness of pregnant women to prepare for labor would be better. The author analyzes that the greater the gestational age of the mother, the frequency of antenatal care visit (ANC) will be more frequent. Padas every time a doctor or midwife visits will provide counseling to mothers about childbirth preparation. The more often the ANC then informasi about childbirth will be stronger. This condition causes the older the gestational age, the better the pregnant women in preparing for labor.
Antenatal Care is a service provided to pregnant women to monitor, support maternal health and detect mothers whether they are normal or having problems. Maternal health services are realized through providing antenatal care at least 4 times during pregnancy, with a minimum time distribution of 1 time in the first trimester (0-12 week gestational age), at least 1 time in the second trimester (12-24 weeks gestational age), and at least 2 times in the third trimester (24 weeks gestation - birth). Antenatal Care is very important for pregnant women to do because it can help reduce maternal and infant mortality. Another advantage is to keep it healthy during pregnancy, childbirth and childbirth, and to have babies born healthy, monitor the possibility of pregnancy risks, and plan optimal management of high-risk pregnancies and reduce morbidity and mortality of maternal and perinatal [7].

\section{Parity}

Analysis of the parity factor for labor preparation obtained a significance value of $p=0.768>0.05$, so it can be concluded that the parity factor has no effect on labor preparation. The results of this study are consistent with previous research by Rahmadani and Utami (2017) that the relationship between parity and labor readiness at the Banguntapan II Public Health Center in Bantul Yogyakarta is a significant relationship. Respondents with primiparous parity had the highest number of labor readiness, as many as 17 people $(73.9 \%)$ [8]. While respondents with multipara parity as many as 11 people $(64.7 \%)$ were not ready for labor. In addition, this study also obtained an Odds Ratio value of 5.194 with a $95 \%$ confidence interval, which means that respondents with primiparous parity. The results of the study stated that some of the respondents actually had just had a pregnancy so they did not have much experience, but in this study mothers who had primiparous parity were actually better equipped to face childbirth. This is because the anxiety possessed by primiparous pregnant women towards pregnancy and childbirth makes the pregnant woman pay more attention to everything related to preparation for labor. Meanwhile multipara pregnant women who already have a lot of experience despite being psychologically prepared but mothers tend to be indifferent to various other preparations that must be prepared in the face of childbirth, this is due to the confidence of the mother because she already has previous experience.

\section{Mathernal and Nenonatal Care Handbook (MCH} Handbook)

Analysis of the MCH Handbook factors on labor preparation obtained a significance value of $p=0.013$ $<0.05$, so it can be concluded that the MCH Handbook factor has a significant direct effect on labor preparation. This is in line with Ainiyah's research (2017) which obtained the results of the non-parametric Spearman Rho statistical test. The use of the $\mathrm{MCH}$ handbook has a moderate relationship with the health behavior of pregnant women with a correlation coefficient (r) of 0.530 and has a significant relationship with the $\mathrm{p}$-value of 0.00 or positive, namely the higher the use of the $\mathrm{MCH}$ handbook, the higher the value of the health behavior of pregnant women [9]. One level of the behavioral domain is application, which is the ability to use material that has been learned in actual 
situations or conditions. Applications contained herein health behaviors in MCH Handbook that has been read by pregnant women understood and done in the form of behavior $[6,10]$. One of the health behaviors of pregnant women contained in the $\mathrm{MCH}$ Handbook is about sticking Delivery planning and complications prevention program stickers.

Delivery planning and complications prevention program is an effort to reduce maternal and infant mortality which is done by increasing the coverage and quality of maternal and child health services by bringing health services closer to the community. The $\mathrm{P} 4 \mathrm{~K}$ program is an activity facilitated by midwives in the village in order to increase the active role of husband, family and community in planning a safe delivery and preparation for complications for pregnant women, including planning for the use of post-copy family planning using stickers as a target notification media in order to improve coverage and quality of health services for mothers and newborns [11]. Thus, pregnant women who have a $\mathrm{MCH}$ book will automatically have $\mathrm{P} 4 \mathrm{~K}$ stickers. By charging sticker $\mathrm{P} 4 \mathrm{~K}$ the safe delivery planning and preparation for facing childbirth complications already planned by any pregnant woman.

Based on Susanti's (2015) research, it is known that most respondents with a good level of knowledge about labor preparation in the category of $78.1 \%$. Plans for selecting birth attendants mostly choose a midwife as a helper, 96.9\%. Preparations for maternal equipment showed $34.3 \%$ were complete [12]. Only $25 \%$ of baby gear has been prepared.maternity savings are ready. Transportation preparation for most mothers has prepared $71.9 \%$. Decision making is known to be mostly carried out based on agreement of husband and wife $59.4 \%$. While the preparation of blood donors is known to most respondents have not prepared.

\section{E. Antenatal Care (ANC)}

Analysis of Antenatal Care factors on labor preparation obtained a significance value of $p=0.434>0.05$, so it can be concluded that the ANC factor does not affect labor preparation. Health services for pregnant women are also called Antenatal Care (ANC), which is health services by professionals for pregnant women during their pregnancy which are carried out in accordance with established antenatal care standards. Antenatal Care Check (ANC) is a pregnancy check up to optimize the mental and physical health of pregnant women, to be able to deal with childbirth, the puerperium, preparation for breastfeeding and the return of reproductive health properly [13].

This contradicts the results of the study of Fitriyani and Dewi (2019) finding an association between the frequency of antenatal care and $\mathrm{P} 4 \mathrm{~K}$ preparation. The results showed that respondents who make regular antenatal care visits have good labor preparation and vice versa, pregnant women who do antenatal care visits do not regularly have poor maternity preparation [14]. Pregnant women who do irregular antenatal visits will risk not preparing $\mathrm{P} 4 \mathrm{~K}$ by 8.40 times higher than mothers who do regular antenatal visits.
Likewise, the results of the study by Suwanti et al (2013) found that out of 79 pregnant women there were 53 people who visited according to gestational age. 26 pregnancy more people choose Non Health Workers who will help childbirth as many as 17 people (65.4\%) [15]. From the results of the analysis test there is a correlation between the frequency of Antenatal Care and the selection of birth attendants. Maini and Trihandini's research (2013) also found that pregnant women with adequate ANC utilization were 6.6 times more likely to deliver in health facilities compared to those without ANC [16].

F. High Risk

Analysis of the factors of gestational age, parity, and ANC on High Risk of Pregnant women, obtained a significance value of gestational age $\mathrm{p}=0.483$, parity $\mathrm{p}=$ 0.039 , and ANC $\mathrm{p}=0.346$, so it can be concluded that only parity affects the risk of maternal pregnancy. Based on the value of $\mathrm{R}^{2}=0.169$ on risk factors, which means that the contribution of factors influence gestational age, parity, and the ANC is only $16.9 \%$, the rest influenced by other factors not entered into this study. Thus the authors analyze that high-risk pregnancy is not a direct factor for pregnant women preparing for labor. However, with pregnant women identified and knowing that their pregnancies are at high risk, the tendency for pregnant women to be more frequent is to consult with health workers both doctors and midwives. High risk pregnancy is one indicator that delivery must be at the health center or in the hospital. So that the mother will be better prepared in preparing for childbirth. This is according to research conducted by Qudriani and Hidayah (2017) Finding Term relationship between pregnant women's perception of high risk pregnancy with compliance do antenatal care.

High-risk pregnancy is a pregnancy that has a greater risk than usual (for both mother and baby) that can result in illness or death before or after delivery. Early detection of pregnancy can be used as an effort to prevent high-risk pregnancies from pregnant women [17]. While risk factors according to Mochtar are young primi, old primi, secondary old primi, youngest child $<2$ years old, multi grande, age $\geq$ 35 years, height $\leq 145 \mathrm{~cm}[18,19]$.

\section{CONCLUSIONS AND SUGGESTIONS}

Conclusions of the study are known factors of education, age, $\mathrm{MCH}$ handbook influence on labor preparation. Meanwhile, parity and Antenatal Care (ANC) factors do not affect labor preparation. Contribution of influence from factors of Education, gestational age, parity, $\mathrm{MCH}$ handbook, High risk, and ANC were $72.4 \%$.

Pregnant women are advised to regularly Antenatal Care and read information in the $\mathrm{MCH}$ handbook. Midwives should provide about childbirth preparation so that every pregnant woman can prepare her labor properly.

\section{ACKNOWLEDGMENTS}

The author conveys an expression of gratitude to the presence of God who is almighty for the completion of this study. The author also thanks the STIKes Respati Tasikmalaya for providing financial support to the head of the Singaparna Public Health Center and the head of the 
Cikunir village for their permission. Hopefully this article is useful for readers in general.

\section{REFERENCES}

[1] Arif Rahadian, "Maternal Death and Mitigation Efforts, the Indonesian Family Planning Association (PKBI)," https://pkbi.or.id/kematian-ibu-and-oper- effort-treatment/ , .

[2] Health Research and Development Agency, "Basic Health Research (RISKESDAS) 2013," Lap. Nas. 2013, 2013, doi: December 1, 2013.

[3] M. M. AM Rosliza, "Male Participation and Sharing of Responsibility in Strengthening Family Planning Activities in Malaysia," Malaysian J. Public Heal. Med., Vol. 10, no. 1, pp. 23-27, 2010

[4] I. P. Suiraoka and I. D. N. Supariasa, Health Education Media. 2012.

[5] Sugiyanti, "Factors Influencing Labor Preparation for Trimester III Pregnant Women at Kustati Islamic Hospital Surakarta," 2009.

[6] S. Notoatmodjo, Health Promotion Theories and Applications. Jakarta: Rineka Cipta, 2005.

[7] Saifuddin, National Reference Book for Maternal and Neonatal Health Services. Jakarta: Bina Pustaka Sarwono Prawiroharjo Foundation, 2009.

[8] U. S. Rahmadani R, "Factors Related to Labor Readiness in Puskesmas Banguntapan II Bantul Yogyakarta."
[9] Ainiyah.N.H, "The Relationship between the utilization of the Maternal and Child Health Book (MCH) and the Level of Knowledge and Behavior of Trimester III Pregnant Mothers' Health at the Puskesmas Jagir Surbaya," Aisyiah University.

[10] S. Notoatmodjo, "Health Communication," Health Promotion Theories and Applications. 2010

[11] Y. A. YulifahR, Community Midwifery Care. Jakarta: Salemba Medika, 2014

[12] S. Susanti, "Description of Pregnant Women Knowledge about the Dangerous Signs of Pregnancy and Childbirth Preparation in Cikunir Village Singapore Area Health Center Tasikmalaya Regency in 2015," 2015.

[13] Manuaba, Midwifery. Jakarta: EGC, 2008.

[14] Dewi Fitriyani, "Relationship between the frequency of antenatal care and labor preparation programs and prevention of complications," J. Obstetrics and Nursing Aisyiyah, vol. 15, no. 1 , pp. 31-36, 2019.

[15] C. D. Suwanti, S Romiastuti, "Relationship between Antenatal Care Frequency (ANC) and Selection of Birth Assistance in Myo Puskesmas Work Area," 2013

[16] Maeni LN and Trihandini I, "Relationship between the use of Ante Natal Care (ANC) and the Selection of Childbirth in Indonesia: Further Analysis of Indonesia Health Demographic Survey 2012," Universitas Indonesia, 2013.

[17] Nurcahyo, High Risk Pregnancy Life and Health. Jakarta, 2007. 